\title{
Two-Stage Batch Adsorber Design for Methylene Blue Removal by Coconut Shell Activated Carbon
}

\author{
Fadina Amran ${ }^{a, b}$, Nur Fatiah Zainuddina, Muhammad Abbas Ahmad \\ Zaini $^{\mathbf{a}, \mathbf{b}, *}$ \\ a School of Chemical \& Energy Engineering, Faculty of Engineering, Universiti \\ Teknologi Malaysia, 81310 UTM Johor Bahru, Johor, Malaysia; ${ }^{b}$ Centre of Lipids \\ Engineering \& Applied Research, Ibnu-Sina Institute for Scientific \& Industrial \\ Research, Universiti Teknologi Malaysia, 81310 UTM Johor Bahru, Johor, Malaysia
}

Abstract The present work was aimed at evaluating the performance of two-stage adsorber for methylene blue removal by coconut shell activated carbon in minimizing the adsorbent mass and contact time. The Langmuir constants were used to evaluate the optimum mass, while the pseudo-second-order constants for contact time. Results show that the adsorbent mass can only be minimized by $0.01 \%$ due to the high adsorbent affinity towards methylene blue, while the contact time has been optimized to $12.2 \mathrm{~min}$ at the studied conditions. The effect of adsorbent affinity in two-stage adsorber was analyzed to shed some light about its importance in the design of two-stage adsorber. The performance evaluation was also discussed to bring insight into wastewater treatment applications.

Keywords: Activated carbon, adsorption, methylene blue, optimization, two-stage adsorber.

*For correspondence: abbas@cheme.utm.my

Received: 2 Jun 2021

Accepted: 8 Nov 2021

(C) Copyright Amran et al. This article is distributed under the terms of the Creative Commons Attribution License, which permits unrestricted use and redistribution provided that the original author and source are credited.

\section{Introduction}

Cocos Nurcriferain or coconut palm is abundantly available around the globe. In Malaysia, the annual coconut production is about $5 \times 10^{5}$ tons, with an average of 5.97 tons per hectare [1]. The vast production and consumption have consequently resulted in the generation of solid wastes, which has shown an increase to $7.34 \times 10^{6}$ tons from all industrial and domestic sectors [2]. In order to lessen the burden of the solid waste management, measures are sought to convert the coconut wastes into sustainable materials such as solid fuel and activated carbon.

Activated carbon has been widely adopted as effective adsorbent in wastewater treatment because of its excellent physicochemical properties to remove pollutants at low concentration [3]. Among others, coconut shell is a promising feedstock of activated carbon because of its hard texture that contains more than $40 \%$ carbon [3]. Generally, the so-called carbonaceous material can be chemically converted into activated carbon at temperatures ranging between $500^{\circ} \mathrm{C}$ and $800^{\circ} \mathrm{C}$ using potassium hydroxide $[4,5]$, sodium hydroxide [6, 7], phosphoric acid [8, 9], zinc chloride [10,11] and calcium carbonate [12, 13].

Several studies have been documented to demonstrate the adsorptive performance of coconut shell activated carbons to remove various water pollutants [14, 15, 16, 17]. Yasin et al. [14] reported a 45.9 $\mathrm{mg} / \mathrm{g}$ removal of methylene blue by $\mathrm{KOH}$-activated coconut shell carbon with a high surface area of 1389 $\mathrm{m}^{2} / \mathrm{g}$. Recently, Oribayo et al. [17] showed a higher removal of methylene blue at $321 \mathrm{mg} / \mathrm{g}$ using $\mathrm{ZnCl}_{2-}$ activated carbon. Nonetheless, the former [14] exhibits a tremendous affinity towards the pollutant, that brings insight into real-scale applications. 
One-stage batch adsorber has been accepted as a standard protocol in adsorption studies. However, the setting is incapable to forecast high removal performance at optimum adsorbent dosage and contact time for process scaling-up. Hence, a two-stage adsorber is designed to simulate the adsorbent mass and contact time in achieving the desired removal percentage at any effluent volume. Palanisami et al. [18] reported a mass reduction of $14 \%$ in a two-stage adsorber of coffee residue activated carbon for phenol removal. The same design also projects the improvement in the mass of date stones by $44 \%$ for malachite green removal [19]. In a related work, the time for methylene blue adsorption is anticipated to decrease from $100 \mathrm{~min}$ to $37.5 \mathrm{~min}$ in a two-stage adsorber of sawdust activated carbon [20]. The present work was aimed to broaden the horizon in a two-stage adsorber design by employing high affinity activated carbon as base-case study [14]. The Langmuir and pseudo-second-order constants were used to establish the profiles of adsorbent mass, contact time and performance evaluation. The findings were discussed to shed light into sustainable wastewater treatment.

\section{Methods}

\section{Adsorption Data}

Activated carbon with specific surface of $1389 \mathrm{~m}^{2} / \mathrm{g}$ was derived from coconut shell by potassium hydroxide activation [14]. The adsorption data for equilibrium and kinetics were fitted into Langmuir and pseudo-second-order models, respectively. The models are expressed as Equations (1) and (2), respectively.

$$
\begin{gathered}
q_{e}=\frac{q_{m} K_{L} C_{e}}{1+K_{L} C_{e}} \\
q_{t}=\frac{q_{e}{ }^{2} k_{2} t}{1+q_{e} k_{2} t}
\end{gathered}
$$

Where, $q_{e}(\mathrm{mg} / \mathrm{g})$ is the capacity at equilibrium, $q_{m}(\mathrm{mg} / \mathrm{g})$ is the maximum capacity at surface saturation, $q_{t}(\mathrm{mg} / \mathrm{g})$ is the capacity at any time, $t(\mathrm{~min}), C_{e}(\mathrm{mg} / \mathrm{L})$ is the equilibrium concentration, $K_{L}(\mathrm{~L} / \mathrm{mg})$ is the sorption affinity, and $k_{2}$ (g/mg.min) is the rate constant. The constants are summarized in Table 1 and were used to simulate the two-stage batch adsorber aimed at capitalizing the adsorbent mass and minimizing the contact time.

Table 1. Langmuir and pseudo-second-order constants [14]

\begin{tabular}{ccccccc}
\hline \multicolumn{3}{c}{ Langmuir model } & & \multicolumn{3}{c}{ Pseudo-second-order } \\
\cline { 1 - 2 } \cline { 5 - 6 } $\begin{array}{c}q_{m} \\
(\mathrm{mg} / \mathrm{g})\end{array}$ & $\begin{array}{c}K_{\mathrm{L}} \\
(\mathrm{L} / \mathrm{mg})\end{array}$ & $\mathrm{R}^{2}$ & & $q_{e}(\mathrm{mg} / \mathrm{g})$ & $\begin{array}{c}k_{2} \\
(\mathrm{~g} / \mathrm{mg} \cdot \mathrm{min})\end{array}$ & $\mathrm{R}^{2}$ \\
\hline 9.97 & 4.64 & 0.99 & & 11.24 & 0.012 & 0.95 \\
\hline
\end{tabular}

\section{Two-Stage Adsorber Design}

In two-stage adsorber, the effluent, $V$ passes through stage-1, in which the mass $m_{1}$ brings the process to equilibrium at concentration $C_{1}$ before the treated effluent enters stage-2, wherein the mass $m_{2}$ brings the process to final equilibrium at concentration $C_{2}$. Figure 1 visualizes the schematic of two-stage batch adsorber design. Each stage is supplied with fresh activated carbon for the same volume of dye to achieve the adsorption capacities, $q_{1}$ and $q_{2}$. The dye concentration declines from $C_{0}$ to $C_{1}$ in the stage1 and $C_{1}$ to $C_{2}$ in stage- 2 . 

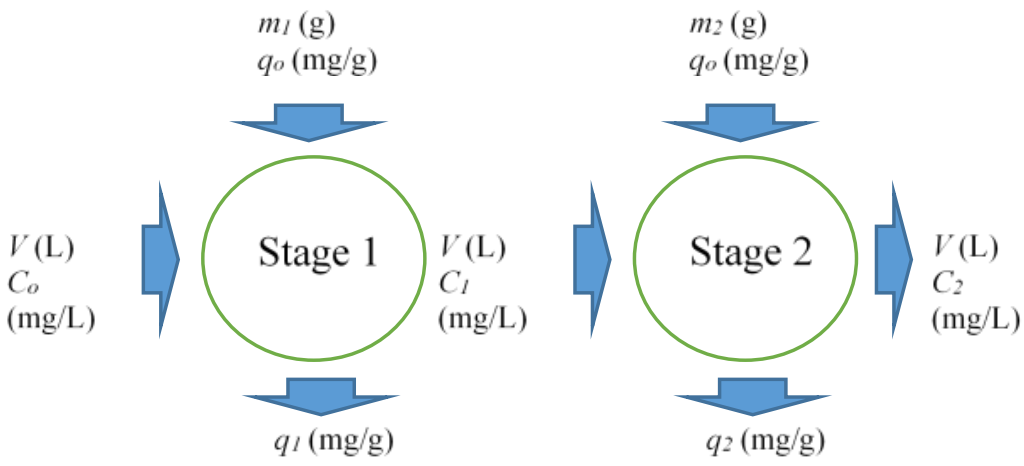

Figure 1. Two-stage adsorber design [21]

The overall process can be represented by mass balance as follows,

$$
V\left(C_{o}-C_{1}\right)=m_{1}\left(q_{1}-q_{o}\right)
$$

For mass optimization, the two-stage adsorber was designed using the following experimental conditions: volume, $V=0.025 \mathrm{~L}$, initial concentration, $C_{0}=100 \mathrm{mg} / \mathrm{L}$, equilibrium concentration, $C_{2}=84$ $\mathrm{mg} / \mathrm{L}$, and adsorbent mass (one-stage adsorber), $m=0.04 \mathrm{~g}$ [14]. A series of sorption system number for $C_{1}$ from 100 to $84 \mathrm{mg} / \mathrm{L}$ in a $1.0 \mathrm{mg} / \mathrm{L}$ step-size was assembled. The mass of activated carbon was calculated for each decrement. For example, in sorption system number 1 , the design objective is to reduce the initial dye concentration from 100 to $99 \mathrm{mg} / \mathrm{L}$ in stage- 1 . Similarly in sorption system numbers 2,3 , and so on, the design objectives are to reduce the initial dye concentration from 99 to $98 \mathrm{mg} / \mathrm{L}, 98$ to $97 \mathrm{mg} / \mathrm{L}$, and lastly down to $84 \mathrm{mg} / \mathrm{L}$. While, in stage-2, the design objective for sorption system number 1 is to reduce the concentration from 99 to $84 \mathrm{mg} / \mathrm{L}$. The same approach applies for determination of minimum contact time. Equation (1) was incorporated in Equation (3) to yield,

$$
\frac{m_{1}}{V}=\frac{\left(C_{O}-C_{1}\right)\left(1+K_{L} C_{1}\right)}{K_{L} q_{m} C_{1}}
$$

and so, for both stages,

$$
\frac{m_{1}+m_{2}}{V}=\frac{1}{K_{L} q_{m}}\left(\frac{\left(C_{O}-C_{1}\right)\left(1+K_{L} C_{1}\right)}{C_{1}}+\frac{\left(C_{1}-C_{2}\right)\left(1+K_{L} C_{2}\right)}{C_{2}}\right)
$$

Equation (5) was differentiated with respect to $C_{1}$ and set $\frac{\left.d\left[m_{1}+m_{2}\right) / V\right]}{d C_{1}}=0$, solving $C_{1}$ as,

$$
C_{1}=\left(C_{O} C_{2}\right)^{1 / 2}
$$

Equation (2) was substituted into Equation (3) to yield expression to compute optimum time required to accomplish the desired methylene blue removal in a two-stage adsorber as,

$$
t=\frac{\left(\frac{1}{q_{e} k_{2}}\right) V\left(C_{o}-C_{t}\right)}{m q_{e}-V\left(C_{o}-C_{t}\right)}
$$

The removal percentage, $R$ was calculated by the following equation,

$$
R=\frac{C_{o}-C_{2}}{C_{o}} \times 100
$$




\section{Results and Discussion}

\section{Mass Optimization}

Figure 2 shows the profile of adsorbent mass to achieve $16 \%$ removal of methylene blue in a two-stage adsorber. Figure 2(a) illustrates a decreasing pattern of adsorbent mass as the sorption system number increases from 1 to 9 due to small intermediate concentration to compensate the equilibrium concentration at stage-2. The optimum mass of $40.0980 \mathrm{~g}$ was obtained at sorption system number 9 . Figure 2(b) depicts the profiles of combined mass in stage-1 and stage-2. Stage-1 displays an increasing pattern, while the opposite is true for stage-2. In a two-stage adsorber design, stage-1 often bears a larger surface load at high concentration driving force to overcome the mass transfer resistance, and consequently, less adsorbent mass would be needed to reach the equilibrium in stage-2 [22]. From the combined mass, the optimum saving of adsorbent mass is only $0.051 \%$ at any effluent volume when compared to one-stage adsorber (sorption system number 1), which is due to the high affinity of activated carbon towards methylene blue $\left(K_{L}=4.64 \mathrm{~L} / \mathrm{mg}\right)$.
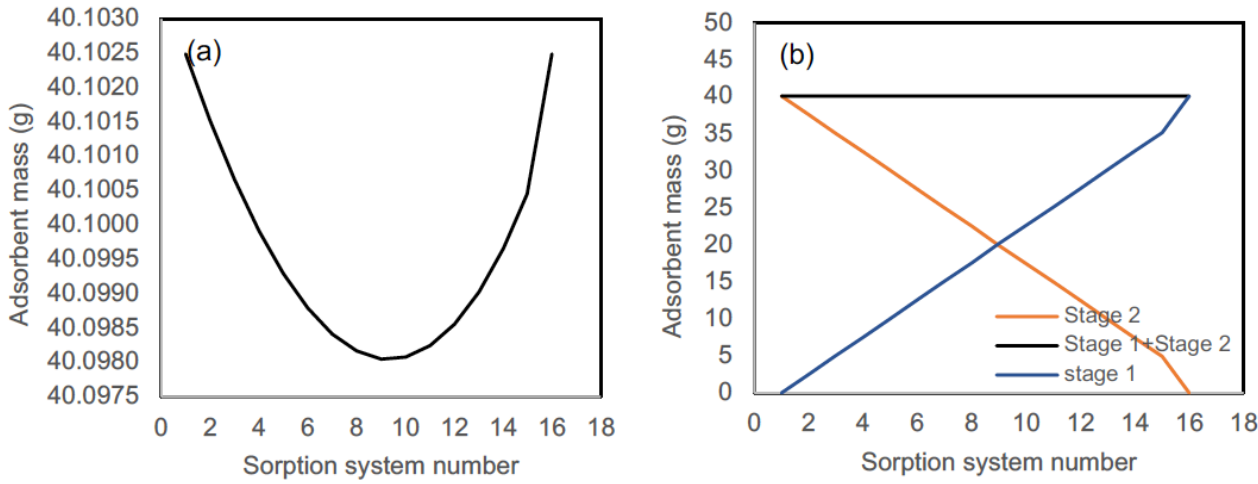

Figure 2. (a) Mass optimization, and (b) profiles of adsorbent mass in stage-1 and stage-2

\section{Time Optimization}

Figure 3 shows the profiles of contact time against sorption system number at optimum mass. The contact time increased with sorption system number in stage-1, while it decreased in stage2. This is associated with the available active sites on the activated carbon surface for dye molecules to bind, and also the driving force as a result of concentration gradient. When the effluent enters stage-2 at lower $C_{1}$, less contact time is required to reach the final equilibrium concentration, $C_{2}$. The optimum contact time is $12.2 \mathrm{~min}$ at sorption system number 9 . The magnitude is rapid when compared to $252 \mathrm{~min}$ (adsorbent mass $=250 \mathrm{mg}$ ) as reported using one-stage adsorber [14].

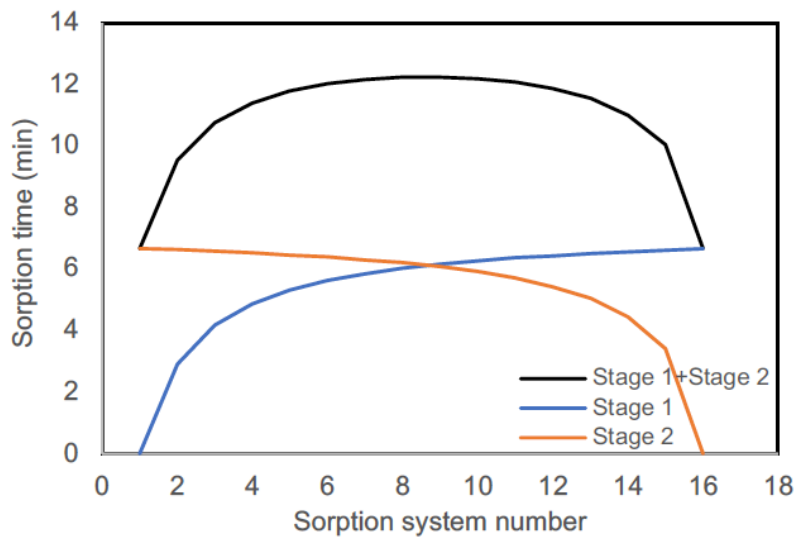

Figure 3. Time optimization at optimum mass 


\section{Performance Evaluation}

Figure 4 shows the effect of initial concentration on intermediate concentration, $C_{1}$ at different target removal percentages and equilibrium concentrations. From Figure 4(a), for $C_{0}=500 \mathrm{mg} / \mathrm{L}$, stage- 1 has to reduce the concentration down to $C_{1}=224 \mathrm{mg} / \mathrm{L}$ to achieve $80 \%$ dye removal, while for $99.8 \%$ removal, stage-1 needs to utilize more adsorbent mass to bring $C_{1}$ to $22.4 \mathrm{mg} / \mathrm{L}$. Similarly, $C_{1}$ increased with $C_{0}$, but $C_{1}$ decreased as the target concentration at stage-2, $C_{2}$ decreases to yield higher adsorption performance as shown in Figure 4(b). A smaller $C_{1}$ as the target removal increases permits the removal of remaining dye concentration in stage-2 at low equilibrium. The profiles bring insight into the effectiveness of two-stage adsorber to accomplish a bigger removal percentage of concentrated effluent from the viewpoint of minimum adsorbent mass.
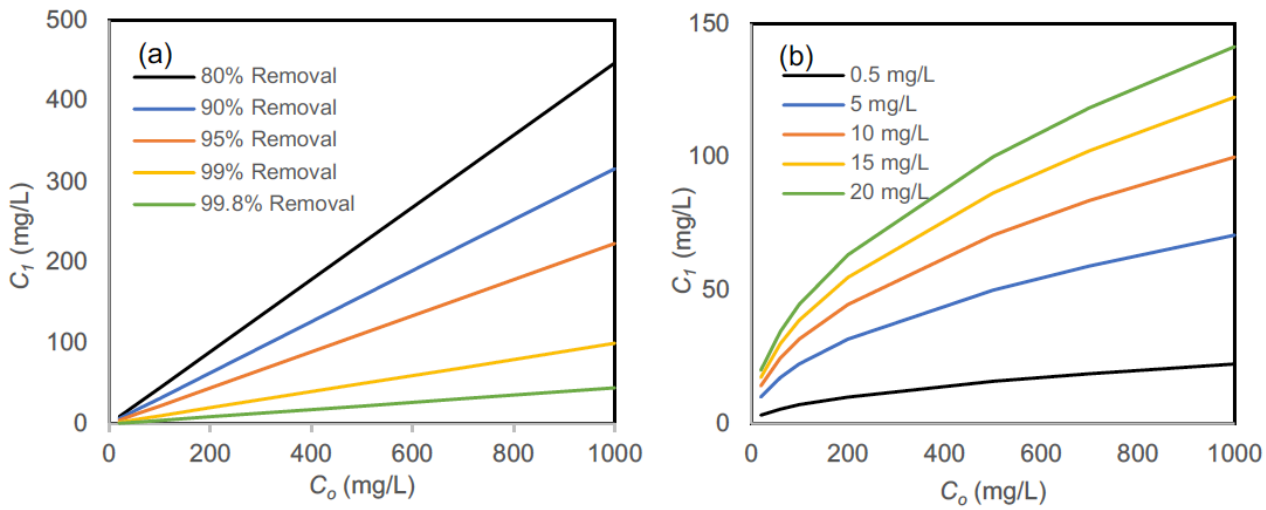

Figure 4. Effect of initial concentration, $C_{o}$ on intermediate concentration, $C_{1}$ at different (a) removal percentages, and (b) equilibrium concentrations, $C_{2}$

Figure 5 shows the effects of $C_{o}$ on the total adsorbent mass for different removal percentages and equilibrium concentrations in two-stage adsorber. The adsorbent mass required to accomplish the methylene blue removal using two-stage adsorber is linearly increased against $C_{o}$ for any target removal percentage, while for any $C_{o}$, the magnitude increased with increasing removal percentage. The higher the removal percentage, the more the mass of coconut shell activated carbon would be consumed for the whole process to provide enough sites for adsorbent-adsorbate interactions leading to adsorption [23]. At any target $C_{0}$, more adsorbent will be consumed to meet the high performance between $80 \%$ and $99.8 \%$. For example, $2007 \mathrm{~g}$ of adsorbent would be needed to bring the performance to $80 \%$, while the amount increased to $2526 \mathrm{~g}$ for $98.8 \%$ removal. A relatively small increase in mass of $26 \%$ could be related to the affinity of coconut shell activated carbon towards methylene blue dye. Figure $5(\mathrm{~b})$ also shows a rising of mass against $C_{o}$, but the lines are visibly overlapping with one another for different target $C_{2}$ between $0.5 \mathrm{mg} / \mathrm{L}$ and $20 \mathrm{mg} / \mathrm{L}$, due to strong adsorption affinity as previously discussed.
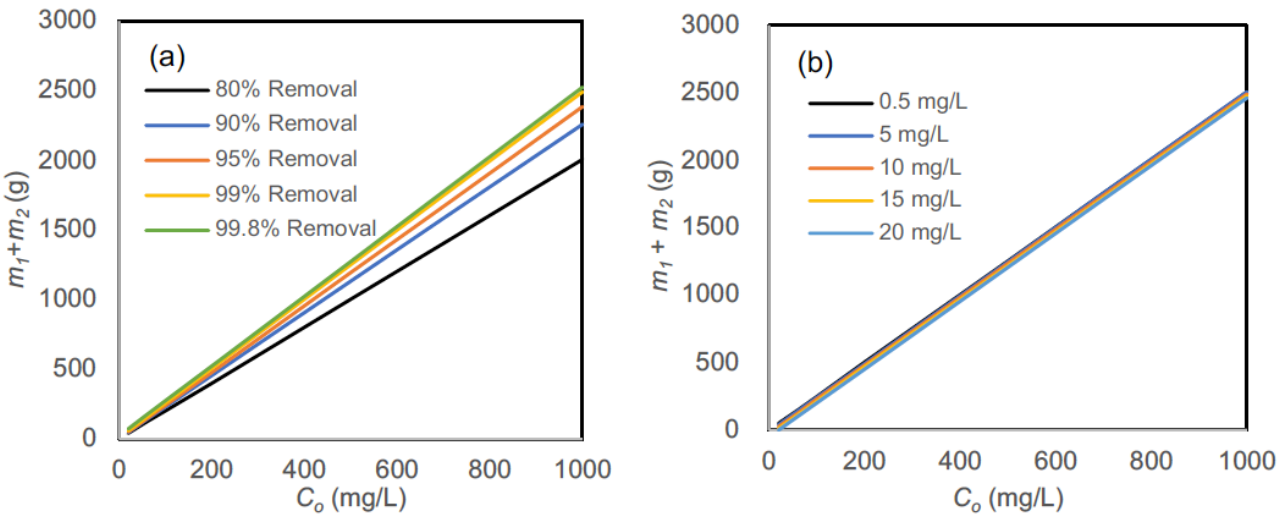

Figure 5. Effect of initial concentration, $C_{o}$ on total mass at different (a) removal percentages, (b) equilibrium concentrations, $C_{2}\left(K_{L}=4.64 \mathrm{~L} / \mathrm{mg}\right)$ 
Figure 6 visualizes the effect of $K_{L}=0.001 \mathrm{~L} / \mathrm{mg}$ on adsorbent mass for different target concentration at stage-2. Obviously, the lower affinity of adsorbent significantly broadens the gap among the target performance with the lower $C_{2}$ actually utilizes greater adsorbent mass for higher performance. At lower affinity, the adsorbent mass has shown a substantially increase of nearly 28 folds from $2426 \mathrm{~g}\left(K_{L}=4.64\right.$ $\mathrm{L} / \mathrm{mg})$ to $68403\left(K_{\mathrm{L}}=0.001 \mathrm{~L} / \mathrm{mg}\right)$ for the target $C_{2}=0.5 \mathrm{mg} / \mathrm{L}$ at $C_{o}=1000 \mathrm{mg} / \mathrm{L}$. It implies the importance of having high affinity adsorbent to fully exploit the benefits of two-stage adsorber while capitalizing the adsorbent mass. The inset in Figure 6 further explains the small increase in adsorbent mass saving for smaller $K_{L}$ values.

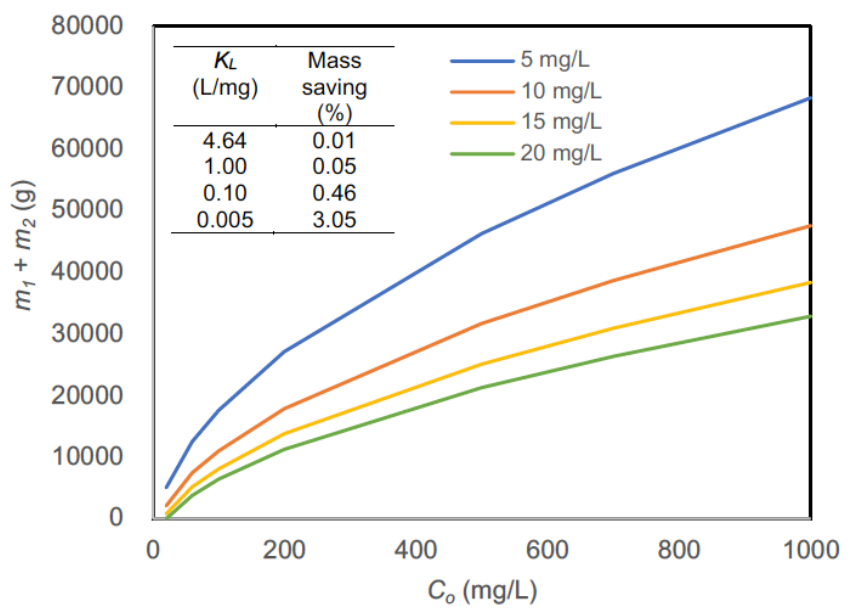

Figure 6. Effect of $C_{o}$ on total mass in two-stage adsorber at different $C_{2}$ for $K_{L}=0.001 \mathrm{~L} / \mathrm{mg}$ (inset: adsorbent mass reduction at different $K_{L}$ )

Figure 7(a) shows the profiles of adsorption capacity at each stage for different removal percentages. The efficiency for methylene blue removal in stage- 2 is always lower than that in stage- 1 as the removal percentage increases because of the lower concentration of dye leaving stage-1. For example, the breakdowns of $99.8 \%$ methylene blue removal are $8 \mathrm{mg} / \mathrm{L} / \mathrm{mg}$ in stage- 1 and $0.36 \mathrm{mg} / \mathrm{L} / \mathrm{mg}$ in stage-2. In other words, stage-2 usually operates at low equilibrium in order to meet the overall desired target performance. Figure $7(\mathrm{~b})$ shows the efficiency in stage-2 for different target $C_{2}$. The efficiency in stage2 increases as $C_{2}$ increases. However, the performance of stage-2 is marginal when compared to that of stage-1. Nonetheless, introducing the stage-2 at higher initial concentration is essential as greater removal percentage can be achieved.
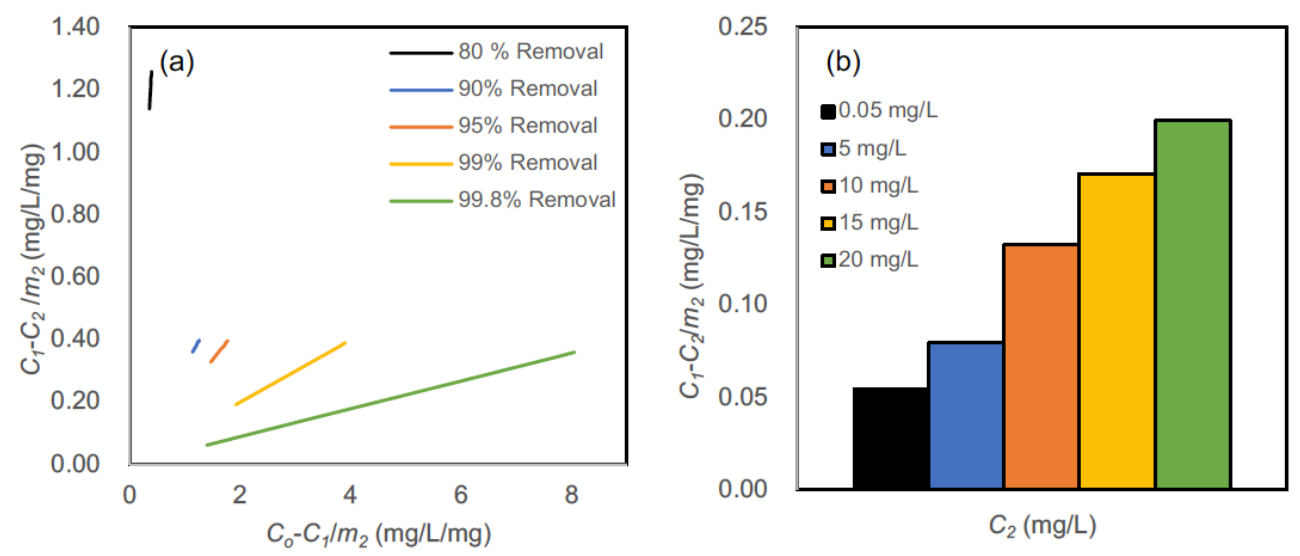

Figure 7. Methylene blue removal at (a) both stages for different removal percentages, and (b) stage-2 for different equilibrium concentrations, $C_{2}$ 


\section{Conclusions}

Coconut shell-based activated carbon was used in the design of two-stage adsorber to simulate the performance evaluation of methylene blue removal in view of optimum adsorbent mass and contact time. Only $0.01 \%$ mass saving can be obtained at any effluent volume because of the high affinity $\left(K_{L}=4.64\right.$ $\mathrm{L} / \mathrm{mg}$ ) of activated carbon, while the contact time can be optimized to $12.2 \mathrm{~min}$ at the studied conditions. The role of affinity in two-stage adsorber has been visualized by the massive increase in adsorbent mass of about 28 folds if the magnitude of affinity is reduced to $0.001 \mathrm{~L} / \mathrm{mg}$ for initial and target concentrations of $1000 \mathrm{mg} / \mathrm{L}$ and $0.5 \mathrm{mg} / \mathrm{L}$, respectively. The performance evaluation at target removal rates enables the prediction of intermediate concentration and profiles of total mass for real implementation in wastewater treatment.

\section{Acknowledgments}

This work was supported by UTM-ICONIC Grant No. 09 G54.

\section{References}

[1] T. K. Hoe, "The current scenario and development of the coconut industry," The Planter, vol. 94, no. 1108, pp. 413-426, 2018.

[2] M. I. M. Masirin, M. B. Ridzuan, S. Mustapha,"An overview of landfill management and technologies: A Malaysian case study at Ampar Tenang," Proceedings $1^{\text {st }}$ National Seminar on Environment, Development \& Sustainability: Ecological, Economical and Social Aspects, Sg. Lang, Selangor, pp. 157-165, 28 - 29 July 2008.

[3] J. Saleem, U. Shahid, M. Hijab, H. Mackey et al., "Production and applications of activated carbons as adsorbents from olive stones," Biomass Conversion and Biorefinery, vol. 9, pp. 775-802, 2019.

[4] S. W. Seo, Y. J. Choi, J. H. Kim et al., "Micropore-structured activated carbon prepared by waste PET/ petroleum-based pitch," Carbon Letters, vol. 29, no. 4, pp. 385-392, 2019.

[5] Z. Asadi-sangachini, M. M. Galangash, H. Younesi et al., "The feasibility of cost-effective manufacturing activated carbon derived from walnut shells for large-scale $\mathrm{CO}_{2}$ capture," Environmental Science and Pollution Research, vol. 26, no. 26, pp. 26542-26552, 2019.

[6] O. Boujibar, A. Souikny, F. Ghamouss et al., " $\mathrm{CO}_{2}$ capture using N-containing nanoporous activated carbon obtained from argan fruit shells," Journal of Environmental Chemical Engineering, vol. 6, no. 2, pp. 19952002, 2018.

[7] Y. Lei, R. Huang, L. Guo et al., "Effect of activating agents on the structure and capacitance performance of tofu derived porous carbon, "Journal of Materials Science: Materials in Electronics, vol. 30, pp. 10274-10283, 2019.

[8] H. Wu, R. Chen, H. Du et al., "Synthesis of activated carbon from peanut shell as dye adsorbents for wastewater treatment," Adsorption Science and Technology, vol. 37, no. 1-2, pp. 34-48, 2018.

[9] J. Baek, H. M. Lee, K. H. An et al., "Preparation and characterization of highly mesoporous activated short carbon fibers from kenaf precursors," Carbon Letters, vol. 29, no. 4, pp. 393-399, 2019.

[10] R. Ma, X. Qin, Z. Liu et al., "Adsorption property, kinetic and equilibrium studies of activated carbon fiber prepared from liquefied wood by $\mathrm{ZnCl}_{2}$ activation," Materials, vol. 12, Article ID 12091377, 2019.

[11] A. O. A, E. Naga, M. E Saied, S. A. Shaban et al., "Fast removal of diclofenac sodium from aqueous solution using sugar cane bagasse-derived activated carbon," Journal of Molecular Liquids, vol. 285, pp. 9-19, 2019.

[12] L. L. Zhi and M. A. A. Zaini, "Potassium carbonate-treated palm kernel shell adsorbent for congo red removal from water," Jurnal Teknologi, vol. 75, no. 1, pp. 233-239, 2015.

[13] N. Alias, M. A. A. Zaini, M. J. Kamaruddin, "Roles of Impregnation ratio of $\mathrm{K}_{2} \mathrm{CO}_{3}$ and $\mathrm{NaOH}$ in chemical activation of palm kernel shell," Journal of Applied Science \& Process Engineering, vol. 4, no. 2, pp. 195-204, 2017.

[14] Y. Yasin, M. Z. Hussein, F. Ahmad, "Adsorption of methylene blue onto treated activated carbon," The Malaysian Journal of Analytical Sciences, vol.11, no. 11, pp. 400 - 406, 2007.

[15] S. Shrestha, G. Son, S. H. Lee et al., "Isotherm and thermodynamic studies of Zn (II) adsorption on lignite and coconut shell-based activated carbon fiber," Chemosphere, vol. 92, no, 8, pp. 1053-1061, 2013.

[16] R. R. Karri, J. N. Sahu, N. S. Jayakumar, "Optimal isotherm parameters for phenol adsorption from aqueous solutions onto coconut shell based activated carbon: Error analysis of linear and non-linear methods," Journal of the Taiwan Institute of Chemical Engineers, vol. 80, pp. 472-487, 2017.

[17] O. Oribayo, O. O. Olaleye, A. S. Akinyanju et al., Coconut shell-based activated carbon as adsorbent for the removal of dye from aqueous solution: equilibrium, kinetics, and thermodynamic studies," Nigerian Journal of Technology, vol. 39, no. 4, pp. 1076 - 1084, 2020.

[18] H. Palanisami, M. R. M. Azmi, M. A. A. Zaini et al., "Coffee residue-based activated carbons for phenol removal," Water Practice \& Technology.

[19] M. Hijab, P. Parthasarathy, H. R. Mackey et al., "Minimizing adsorbent requirements using multi-stage batch adsorption for malachite green removal using microwave date-stone activated carbons," Chemical Engineering and Processing - Process Intensification, Article ID 108318, 2021. 
[20] Markandeya, A. Singh, S.P. Shukla et al., "Adsorptive capacity of sawdust for the adsorption of MB dye and designing of two-stage batch adsorber," Cogent Environmental Science, vol. 1, no. 1, Article ID 1075856 , 2015.

[21] M. A. K. Anuar, N. S. Mahat, N. M. Rusli et al., "Insight into the optimization of mass and contact time in twostage adsorber design for malachite green removal by coconut shell activated carbon.

[22] F. M. Mohammed, E. P. L. Roberts, A. K. Campen et al., "Wastewater treatment by multi-stage batch adsorption and electrochemical regeneration," J. Electrochem. Sci. Eng, vol. 2, no. 4, pp. 223-236, 2012.

[23] S. M. S. Bamatraf and M. A. A. Zaini, "Optimization in a two-stage sorption of malachite green by date palm residue carbon." 